NBSIR 82-1669

\begin{tabular}{l} 
MEASUREMENT OF ELECTROMAGNETIC \\
RADIATION FROM ELECTRIC-RAIL CARS \\
\hline
\end{tabular}

John W. Adams

National Bureau of Standards

U.S. Department of Commerce

Boulder, CO 80303

August 1982

100

.456

$32-1669$

1982 


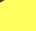




\section{MEASUREMENT OF ELECTROMAGNETIC RADIATION FROM ELECTRIC-RAIL CARS}

John W. Adams

Electromagnetic Fields Division National Engineering Laboratory National Bureau of Standards U.S. Department of Commerce Boulder, CO 80303

August 1982

Prepared for:

Department of Transportation

Research and Special Programs Administration

Transportation Test Center

Cambridge, MA 02142

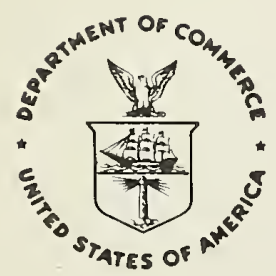

U.S. DEPARTMENT OF COMMERCE, Malcolm Baldrige, Secretary 



\section{CONTENTS}

Page

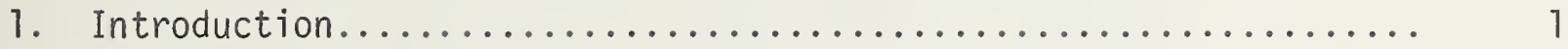

2. Measurement Needs.................................. 2

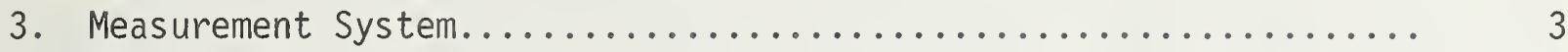

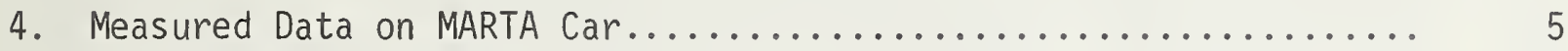

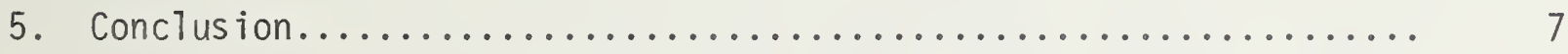



MEASUREMENT OF ELECTROMAGNETIC RADIATION FROM ELECTRIC-RAIL CARS

John W. Adams

Existing Electromagnetic Compatibility (EMC) standards are not directly applicable for measuring Electromagnetic Interference (EMI) from an electric-rail vehicle. This report describes a measurement system and procedure that have potential for making the needed measurements on a moving vehicle. This system and procedure need further evaluation, use and improvement before they could be considered for general use. The problems that were considered are discussed, and those that need additional work are given. Sample measured data from a Metropolitan Atlanta Rapid Transit Authority (MARTA) rail car are given. The measurements were performed at the Department of Transportation Test Center near Pueblo, Colorado.

Key words: EMC; EMI; electric-rail vehicle; EM radiation of electric-rail cars.

\section{Introduction}

These measurements were performed for the Department of Transportation (DOT) and the Transportation Systems Center (TSC) to determine radiated electromagnetic signals from a moving electric-rail vehicle, and to test a measuring system that has the potential of greatly speeding up the measurements process. The capabilities of this measurement system were also studied.

The National Bureau of Standards (NBS) had a consulting contract with DOT, TSC, and in response to an urgent request, NBS undertook to make electromgnetic interference (EMI) measurements on short notice at the Transportation Test Center (TTC) near Pueblo, Colorado. A prototype measurement system was hastily assembled to make the measurements and to also determine the capability of the system to collect and process data quickly. Because of the time element only a minimum of the software was developed prior to the measurements, and much additional software work is needed to fully evaluate the capabilities of the measurement system.

This report addresses the key factors concerning the measurement of electromagnetic radiation from electrically-powered rail cars. It discusses possible relevance of existing electromagnetic compatibility (EMC) standards. It describes a measurement system and procedure that are efficient to use, can be calibrated to give 
absolute field strength levels traceable to the NBS, and are applicable to electrically-powered rail car EMI measurements. Some of the measured results are given for a Metropolitan Atlanta Rapid Transit Authority (MARTA) rail car that was tested at the TTC. The cooperation of TSC and TTC personnel is greatly appreciated.

\section{Measurement Needs}

Several existing EMC standards were reviewed to determine their applicability to measuring EMI from a moving electric-rail vehicle, and it was concluded that none of these standards can be directly applied for the following reasons:

1. Existing standards only provide for testing stationary objects. Only limited power can be applied to a stationary electric-rail vehicle. Electromagnetic (EM) radiation usually increases as more power is applied, giving worst-case levels at maximum acceleration (or deceleration for regenerative braking). This requires testing a moving vehicle.

2. Electric rails are EM transmission lines and form part of a car-rail radiating structure. None of the existing standards provide for testing vehicles on rails.

The following standards were reviewed to determine their applicability and mitations toward this particular measurement problem:

1. MIL STD $461-462$

2. SAE J551F

3. CISPR 2 and 18

4. VDE $871 / 3.68,877 / 1 / 12.59,877 / 2 / 12.55$

5. FCC Dockets 20780 and 80284

6. ANSI C63.4

7. IEEE STD 302-1969. 


\section{Measurement System}

There are many facets that must be considered for a measurement system for electric-rail cars. The system described is an evolution of a basic EMC measurement system plus knowledge gained while making or assisting with measurements at TTC on two rail cars. Additional improvements can and probably will be made by subsequent workers.

Measurement system objectives were as follows:

1. Since the test object was moving and the measuring system was stationary, it was necessary to make measurements as quickly as possible. A moving test object severely limits available time for measurements. By automating the measuring system and using a computer to process the data, absolute data and plots can be generated almost as quickly as relative data; this improvement is a great time saver.

2. Measure absolute field strength levels as accurately as possible with a stated measurement uncertainty. The option of having the system calibrated and traceable to NBS is a relatively straight-forward option.

The location of the measurement-system antennas relative to the test vehicle is influenced by two main factors. First, the vehicle radiates in an unknown and irregular pattern over a hemisphere. Since the vehicle must move, a large arc can be subtended with stationary measurement antennas. Second, the minimum distance from the antennas to the test vehicles must be small enough that the radiated signal from the vehicle is greater than either background ambient or measurement system noise level. If either of these background levels is higher than the radiated signal, either the background level(s) must be lowered or the distance decreased between antennas and test vehicle or a combination of both. This proximity of antennas to the test object can lead to a need for near-field corrections. If minimum distance is greater than half a wavelength, near-field corrections are not necessary. A nominal distance of 16 meters (50 feet) is recommended when measuring frequencies above $10 \mathrm{MHz}$. 
At distances closer than one sixth of a wavelength, near-field measurement conditions prevail. Below $3 \mathrm{MHz}$, a 16-meter separation distance places the antennas in the near field. Since rail vehicles do radiate substantially at frequencies below $1 \mathrm{MHz}$, there is no practical way to avoid near-field conditions. In this portion of the spectrum, measurement distances should be carefully recorded, as fields vary inversely with the third power of the distance as compared inversely with distance in the far field.

If there are specific situations where the EMI may cause a problem at distances less than 16 meters from the rails, measurements should be made at the closer distance rather than extrapolating from 16-meter data.

The question of whether to use field intensity meters (FIM) or spectrum analyzers can be decided on the basis of time required to make the measurements (in most cases). A spectrum analyzer that is IEEE-488 BUS compatible so that it can quickly transfer digitized data to a computer and/or tape is the key to reducing measurement time. Raw data from the spectrum analyzer (or FIM) is relative data which does not include the antenna factors, cable loss, and mismatch factors at each frequency. These unknowns can be added as corrections by a digital computer based on either manufacturer's antenna factors or by an NBS system calibration. A spectrum analyzer system can be about 100 times faster than a FIM system; however, there are certain cases where the FIM system should be used. If there is more than one signal $60 \mathrm{~dB}$ above other signals, intermodulation distortion products may appear in the spectrum analyzer. The FIM, however, has preselection filtering that can usually handle strong out-of-band signals. If very low level signals must be measured at frequencies below $100 \mathrm{MHz}$, the FIM's have better sensitivity and can be used to measure signals not detectable by spectrum analyzers. Background ambient is usually so high at these low frequencies, especially around metropolitan areas, that there is no need for this better sensitivity. At higher frequencies the spectrum analyzers may have better sensitivity.

The frequency range of interest may be from $100 \mathrm{~Hz}$ to $1 \mathrm{GHz}$. This frequency range is far greater than can be covered by one antenna. The antenna is the transducer that converts electric field strength $(E)$ or magnetic field strength $(H)$ into voltage detectable by a spectrum analyzer or FIM. Typically, an electric dipole 
is used to detect $E$ while a shielded loop is used to detect. H. If unperturbed, farfield conditions exist, either parameter, $\mathrm{E}$ or $\mathrm{H}$, can be measured and the other parameter calculated, since the two are related in a known way. As a practical matter, $\mathrm{H}$ is usually measured below $30 \mathrm{MHz}$, while $\mathrm{E}$ is measured above $30 \mathrm{MHz}$. Three orthogonal orientations of the antenna are used, since in EMI measurements the orientation of the vector, $E$ or $H$, is not known.

A single-frequency $(\mathrm{cw})$ source has all of its energy at one discrete frequency. The measure of its amplitude is independent of the receiver bandwidth. A broadband distributed source spreads its energy across a portion of the spectrum. The measure of its amplitude is proportional to the receiver bandwidth, or a factor related to the bandwidth. This is a very complicated factor, since the bandwidth factor depends on the filter and type of detector in the receiver, and the coherence of the measured signal. Some of these complications can be avoided by reporting the bandwidth of the receiver used for the measurement. A spectrum analyzer was used for these measurements. Its $3-\mathrm{dB}$ bandwidth is shown on each figure in this report. If the impulse bandwidth of the spectrum analyzer is desired, an approximation can be made by multiplying the $3-d B$ bandwidth by 1.5. Impulse bandwidth is difficult to measure.

The measurement system (see figure 1) consists of one of several antennas, baluns if needed, either a spectrum analyzer or a FIM, connecting cables (always use the same cable from antenna to receiver), a minicomputer, and appropriate magnetic tape recorder and/or plotter. Either by hand or computer, the correction factors must be added to convert voltage from the receiver to field strength units. The correction factor consists of antenna factor, cable loss, and mismatch factor. It varies substantially with frequency.

\section{Measured Data on MARTA Car}

Data was measured at four different sites under various conditions. This was more than necessary, but part of the effort was to determine a11 sources of EMI so as to correctly identify problem areas.

Two of the locations were adjacent ( 8 meters) to power substations, directly over buried power cables, and over 100 meters away from the rails. Ambient EMI at these locations was high enough to mask any radiation from the rail vehicles. Power substations are not unique to electric vehicles, so these results are not of principal interest. They were measured for background information. The CTA substation was 12 kV; substation \#2 was $115 \mathrm{kV}$; \#2 had higher levels, including some corona radiation. 
The rail-car data was taken with the antennas about 16 meters from the rail centerline; the third rail (power rail) was about 15 meters from the antennas. The data near the CTA substation may have been contaminated by a thunderstorm. The data near substation \#2 may have been contaminated by corona.

The measurement locations are identified by number on figure 2. Use the following chart for location keys:

Location

\#

18 meters from CTA substation

2. 16 meters from rail near CTA substation

3. 7 meters from substation \#2

4. 16 meters from rail near substation \#2.

Two measurement systems were used. The first was a Fourier-transform system that measured from $100 \mathrm{~Hz}$ to $100 \mathrm{kHz}$. Two frequency ranges were used: 0 to $2 \mathrm{kHz}$ and 0 to $100 \mathrm{kHz}$. These records were recorded as raw data on plots but not on magnetic tape. Therefore, correction factors would have to be added by hand. The correction curve (figure 3) was generated by calibrating the measurement system at NBS. The units in figures $4 \& 5$ are in dBV. The correction factor from figure 3 must be added point-bypoint to those figures with amplifier gain $=10$. If the amplifier gain was 100 , subtract $20 \mathrm{~dB}$ from the correction factors obtained from curve 3 before adding.

Data from the second system was recorded on magnetic tape, and correction (calibration) curves were applied via the computer to most of the curves. Selected data showing the measured magnetic fields are shown in figures 6 through 11 . The units of $H$ are $d B$ above a microampere per meter. These curves were produced by pointby-point addition of the raw data curve with the appropriate calibration curve for the particular antenna, balun, and cable used. The ambient measurement system provides a bound to the actual fields. In metropolitan areas these levels may be exceeded. The TTC facility is in a relatively isolated area and the ambient noise levels there are low. 
Between 0.5 and $4 \mathrm{MHz}$ and a distance of 16 meters from the rails, measured signals from the vehicle were sometimes as much as $10 \mathrm{~dB}$ above ambient. Above $8 \mathrm{MHz}$, there were occasional impulses above ambient, but no steady state increase above ambient; below $0.5 \mathrm{MHz}$ the signals were sometimes $20 \mathrm{~dB}$ above ambient.

\section{Conclusion}

The data show an increase in the magnetic field strength of about $10 \mathrm{~dB}$ above system ambient from 1 to $3 \mathrm{MHz}$ and approximately $5 \mathrm{~dB}$ from 4 to $7 \mathrm{MHz}$. If fields at distances closer than 16 meters are in question, additional measurements would be needed. The electric field strength was only measured at frequencies above $20 \mathrm{MHz}$ and at these frequencies the only signals detected were occasional impulses of extremely short duration.

The automated measurement system shows great promise, but additional measurements should be made in a metropolitan area to further evaluate possible intermodulation problems due to other strong transmitters. Before this is done, the software and written measurement procedures should be further refined.

A major problem in measuring fields from a moving vehicle when the measurement system is stationary is the limited amount of time in which to make the measurements. Repeated passes may be necessary. However, if a battery-operated portable system could be installed on board the vehicle, the measurement procedures could be changed and the measurement time might be significantly reduced. An inverter might be used to provide $60-\mathrm{Hz}$ power for the measuring system, but it would have to be adequately shielded and filtered since most inverters are very strong sources of EMI.

There is much additional data available in the form of several hundred plots. If interested, contact the author. 


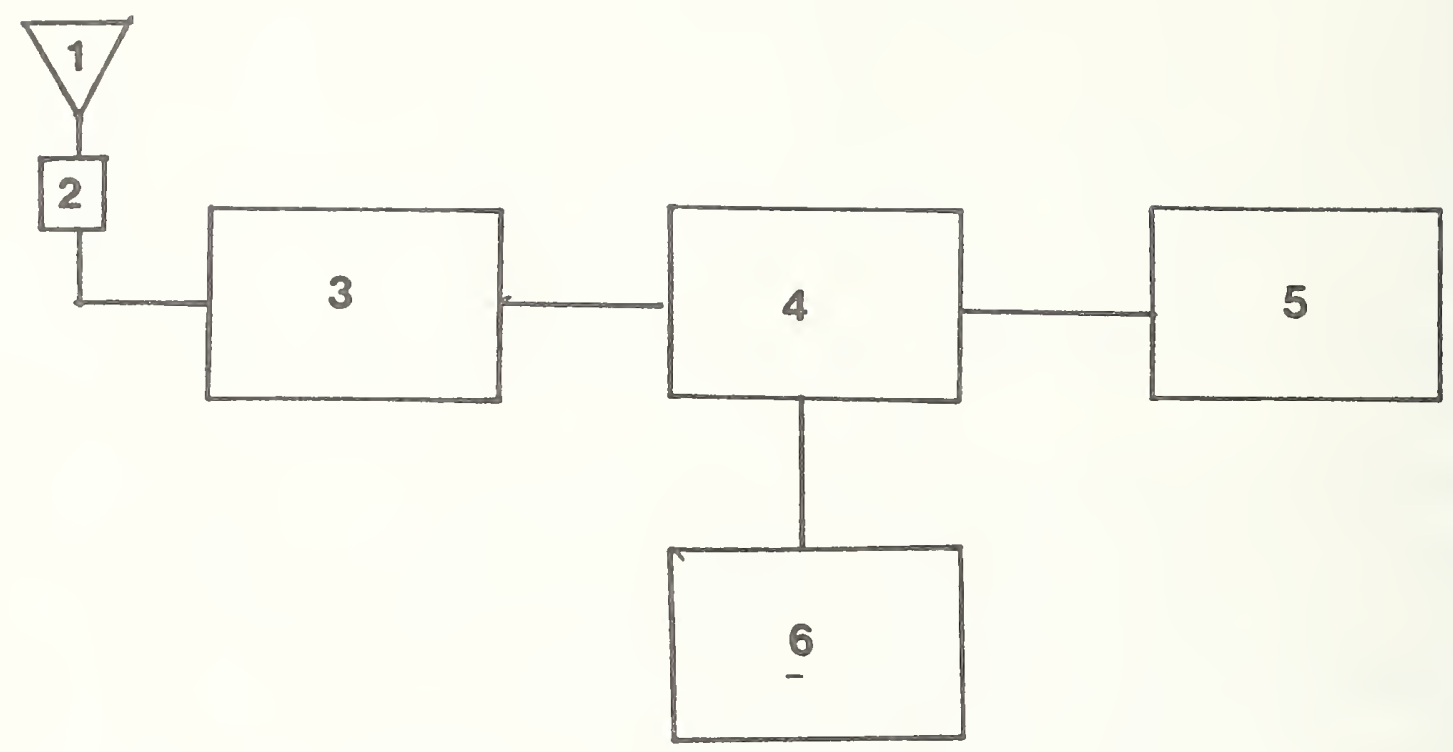

Figure 1. Block Diagram of Measurement System

1. Antenna, loop for $H$ or dipole for $E$.

2. Balun to match impedances and balanced antenna to unbalanced line 3. Receiver, either a spectrum analyzer or a field intensity meter.

4. Minicomputer.

5. Plotter.

6. Recorder, either cassette or floppy disk. 


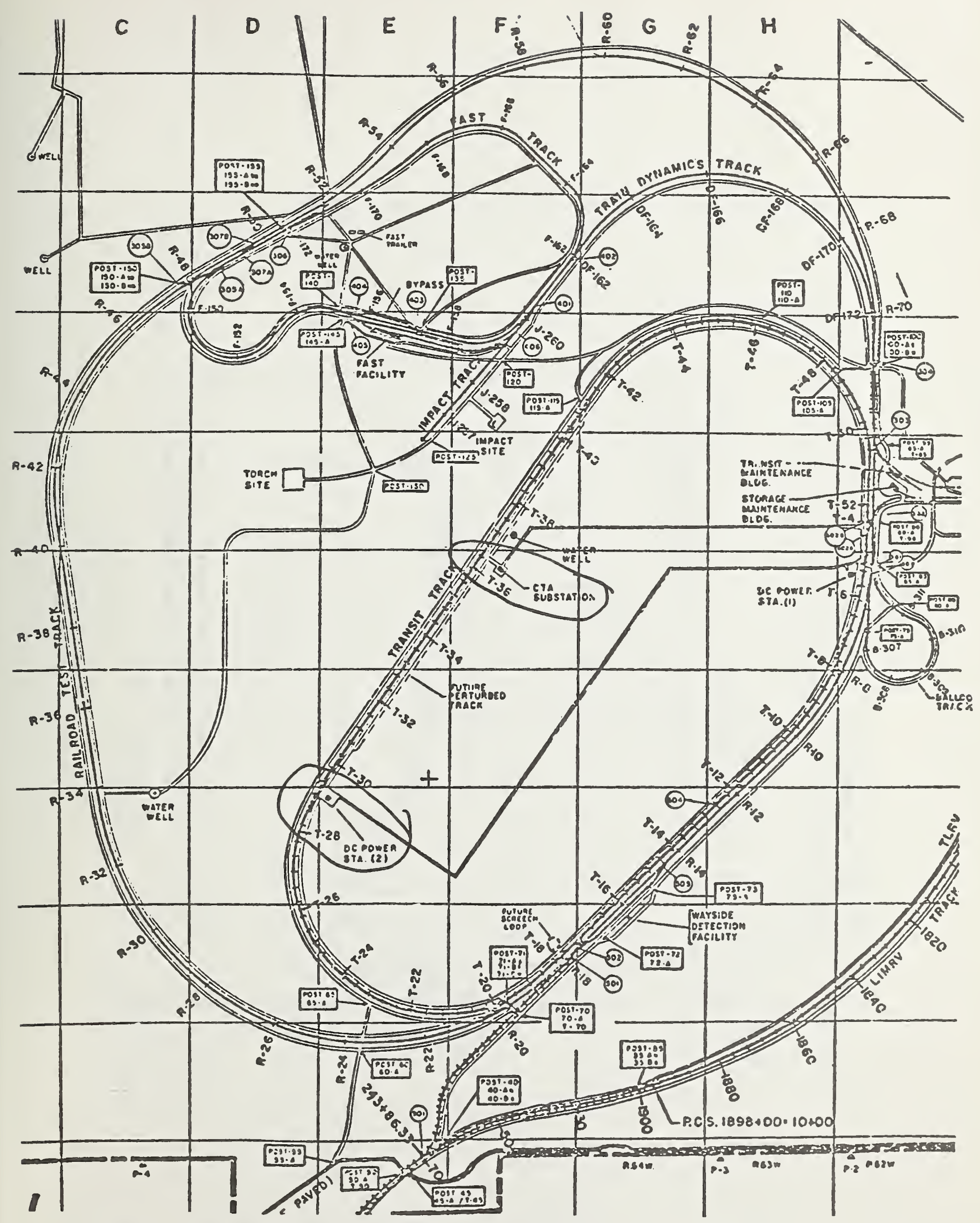

Figure 2. Transportation Test Center 


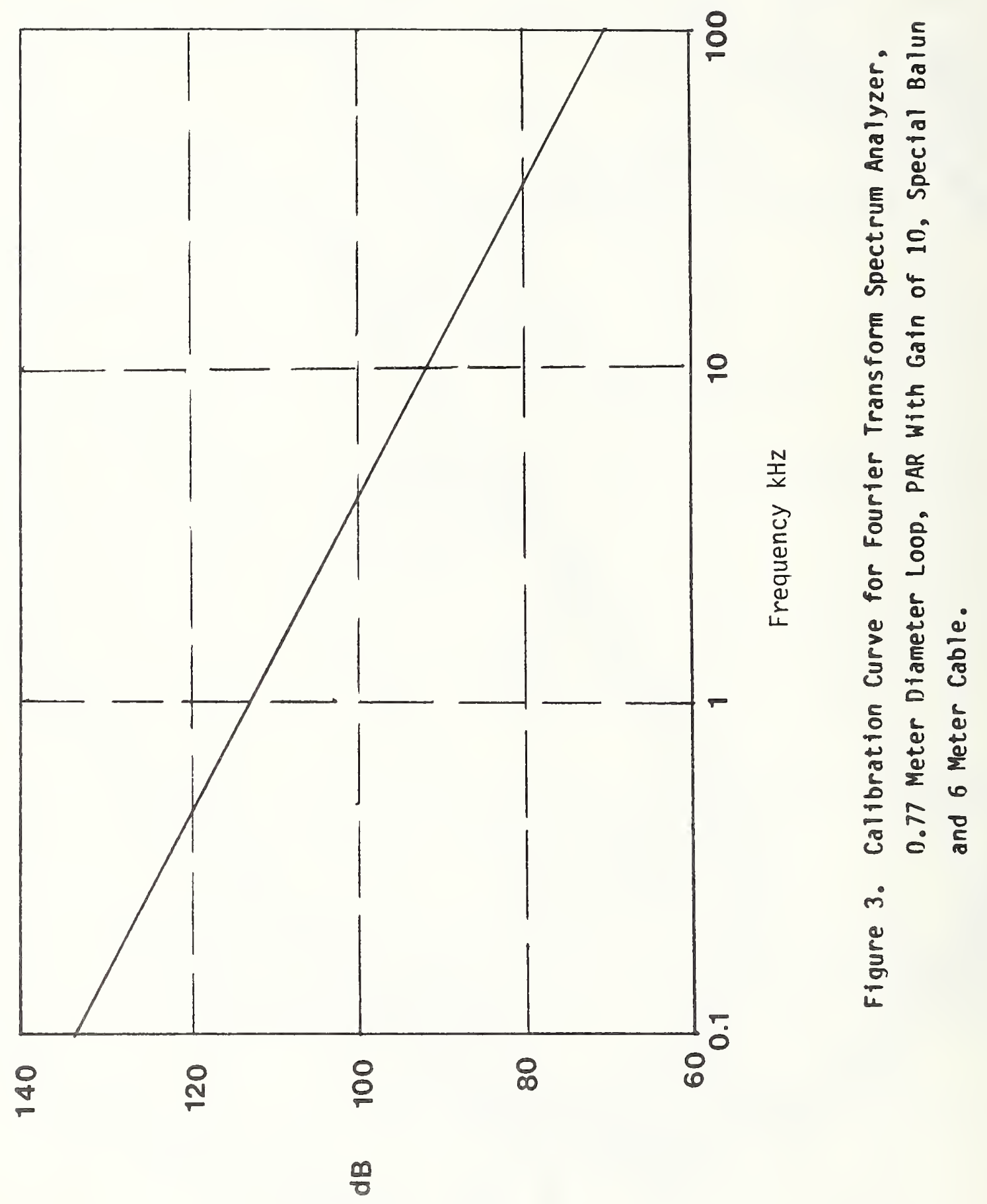




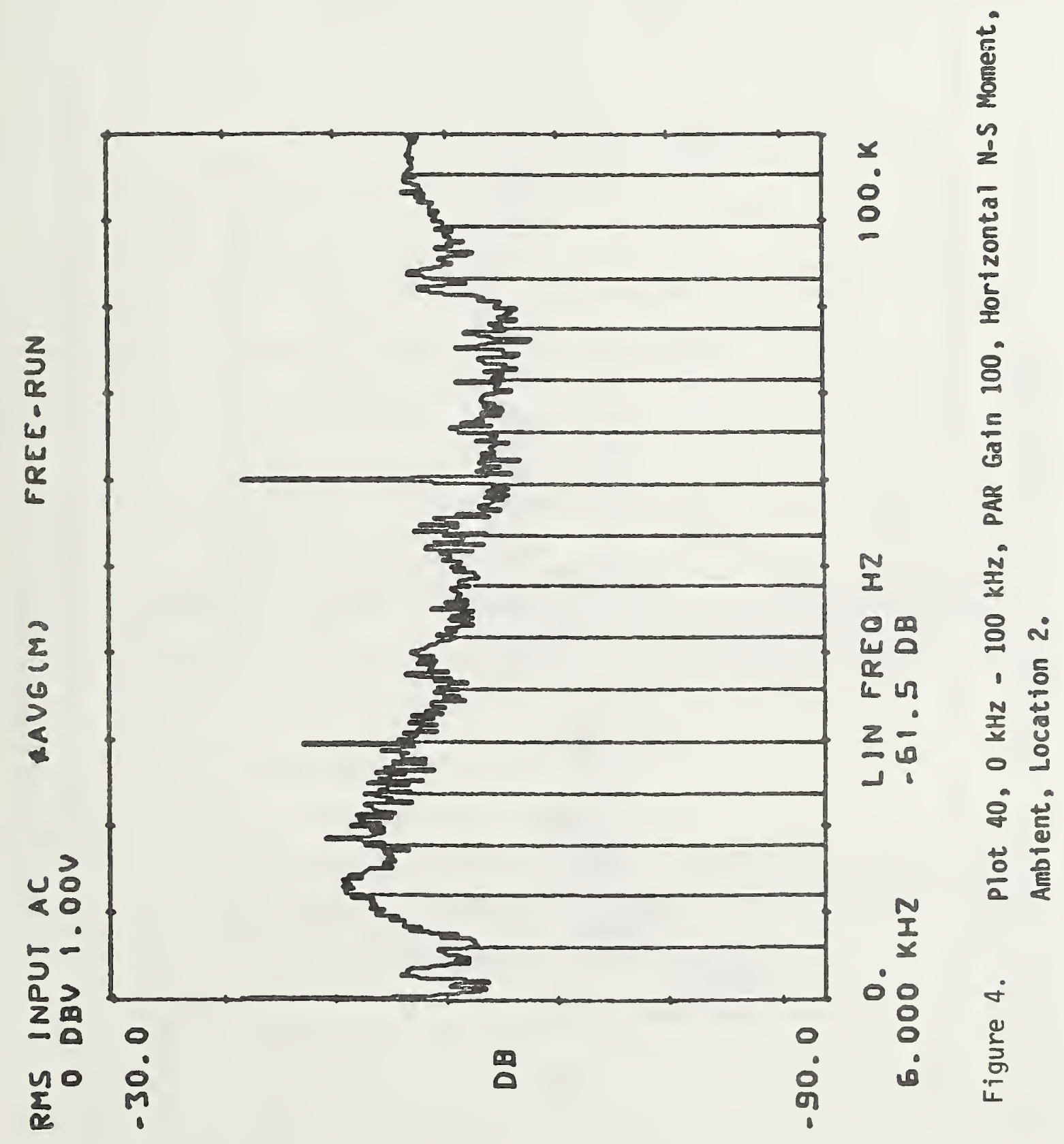



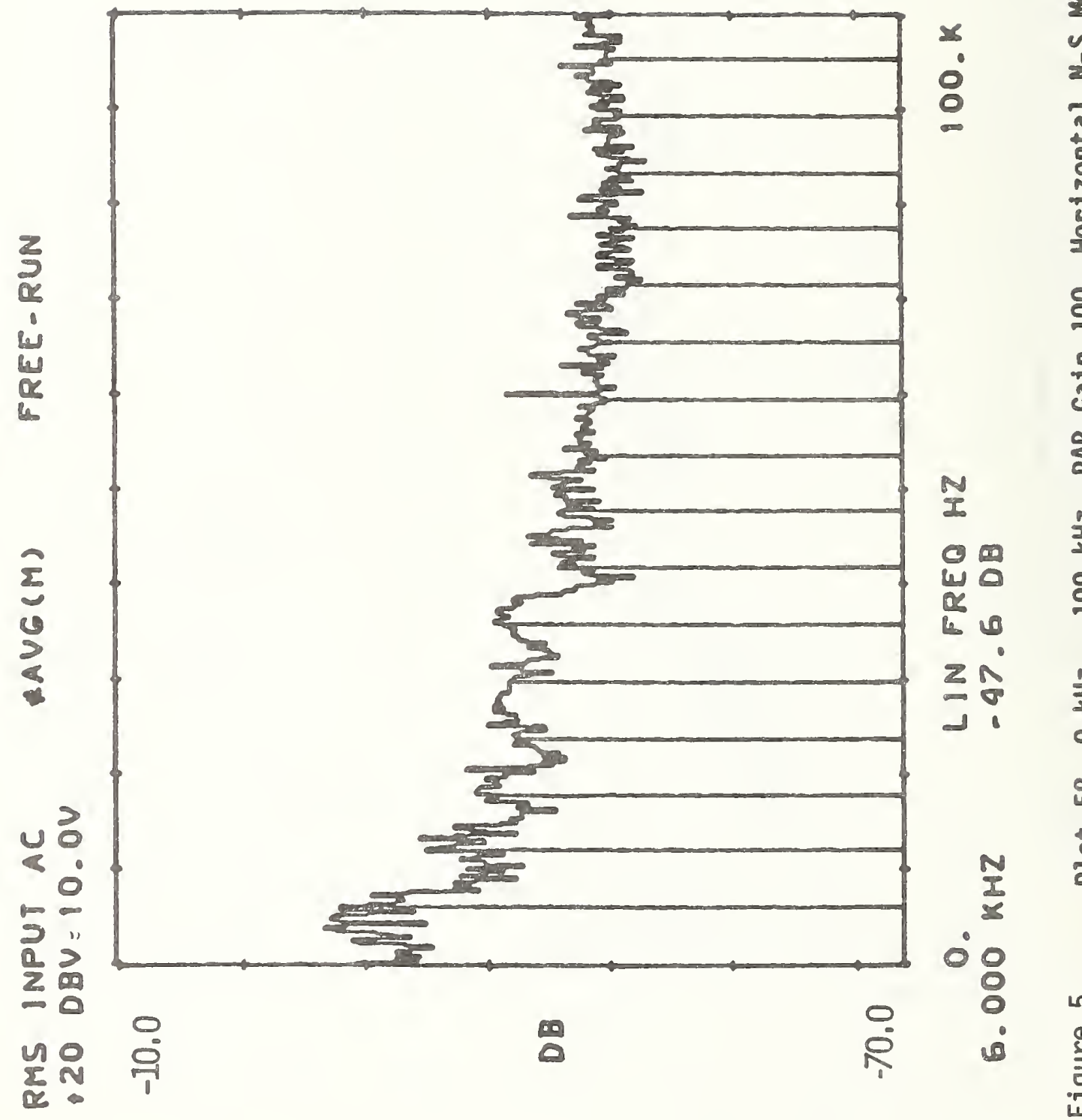

응

용

$\frac{\alpha}{2}$

I

ํํํ 옹

c. 6

a

เ 10

○

- 1

N

$=0$ Nㅜㄴ

- 0 ú

$\infty$

+ E

$\frac{1}{2} \frac{0}{2}$

0

0
0
0 


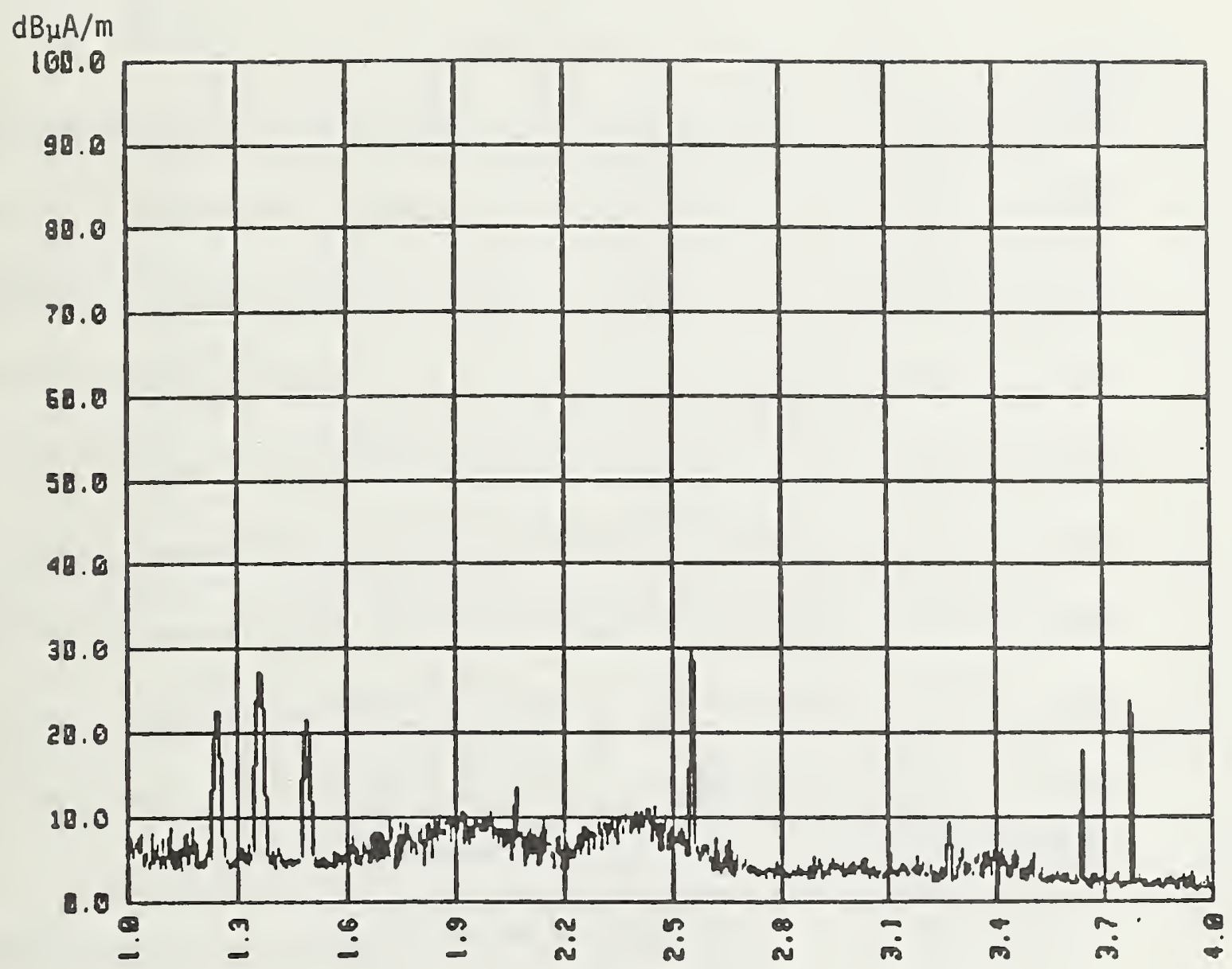

The

Figure 6. File 73, $1 \mathrm{MHz}$ - $4 \mathrm{MHz}$, Horizontal E-W Moment, H-field, Reference Level $97 \mathrm{~dB}{ }_{\mu} \mathrm{V}, \mathrm{RBW} 10 \mathrm{kHz}, \mathrm{VBW} 10 \mathrm{kHz}, 90 \mathrm{millisecond} \mathrm{sweep} \mathrm{time,}$ Maximum Acceleration, Location 2. 


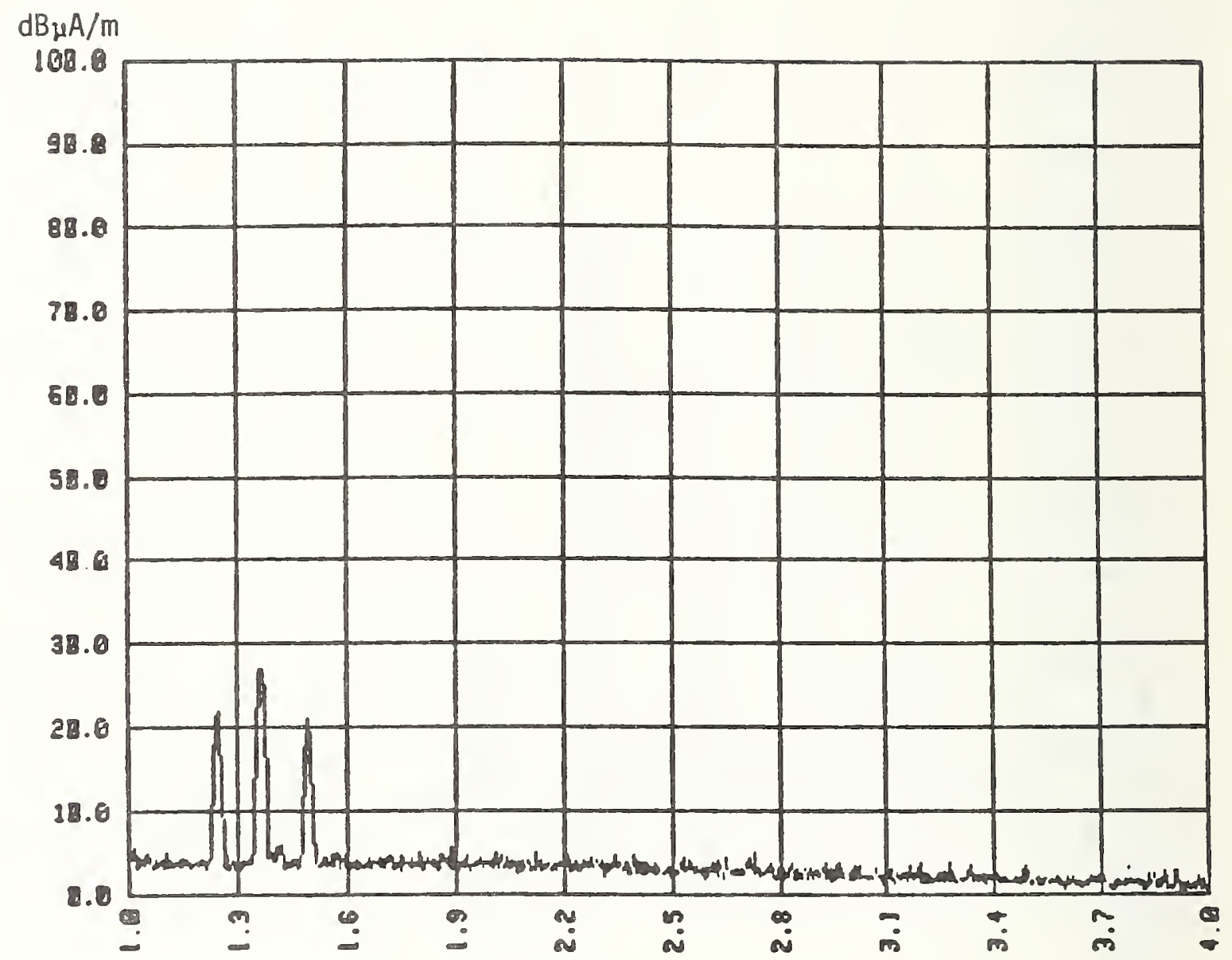

The

Figure 7. File 62, $1 \mathrm{MHz}-4 \mathrm{MHz}$, Horizontal E-W Moment, H-field, Reference Level $97 \mathrm{~dB} \mu \mathrm{V}, \mathrm{RBW} 10 \mathrm{kHz}$, VBW $10 \mathrm{kHz}, 90$ millisecond sweep time, Ambient, Rail Hot, Location 2. 


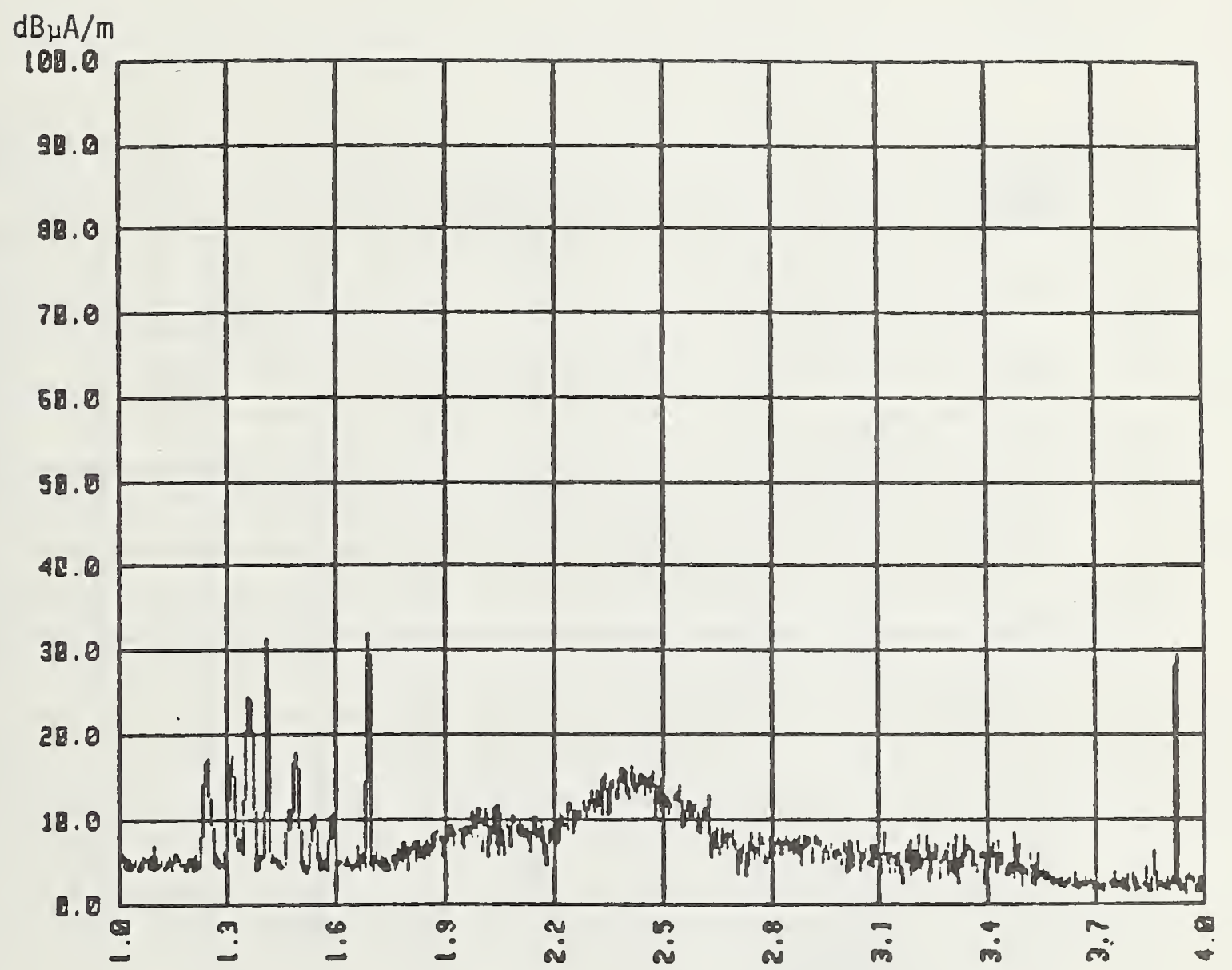

Figure 8. File 72, I MHz - $4 \mathrm{MHz}$, Horizontal N-S Moment, H-field, Reference Level $97 \mathrm{~dB} \mu \mathrm{V}, \mathrm{RBW} 10 \mathrm{kHz}, \mathrm{VBW} 10 \mathrm{kHz}, 90 \mathrm{millisecond} \mathrm{sweep} \mathrm{time,}$ Maximum Acceleration, Location 2. 


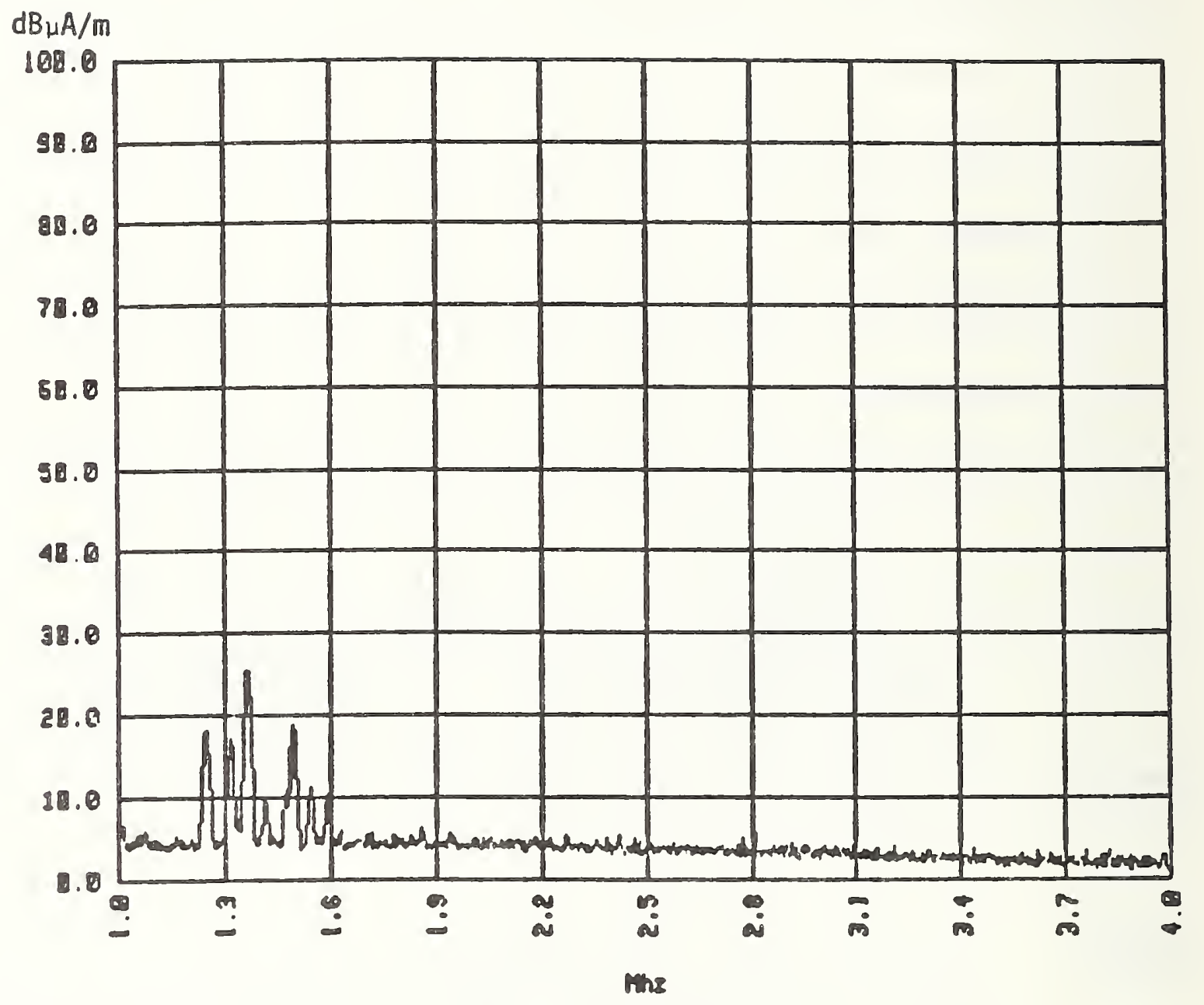

Figure 9. File 61, I Mz - 4 Mtz, Horizontal M-S Moment, H-field, Reference Level $97 \mathrm{~dB}, \mathrm{~V}, \mathrm{RBW} 10 \mathrm{KHz}, \mathrm{VBH} 10 \mathrm{kHz}, 90 \mathrm{~m} 1 \mathrm{ll}$ isecond sweep time, Ambient, Rail Hot, Location 2. 


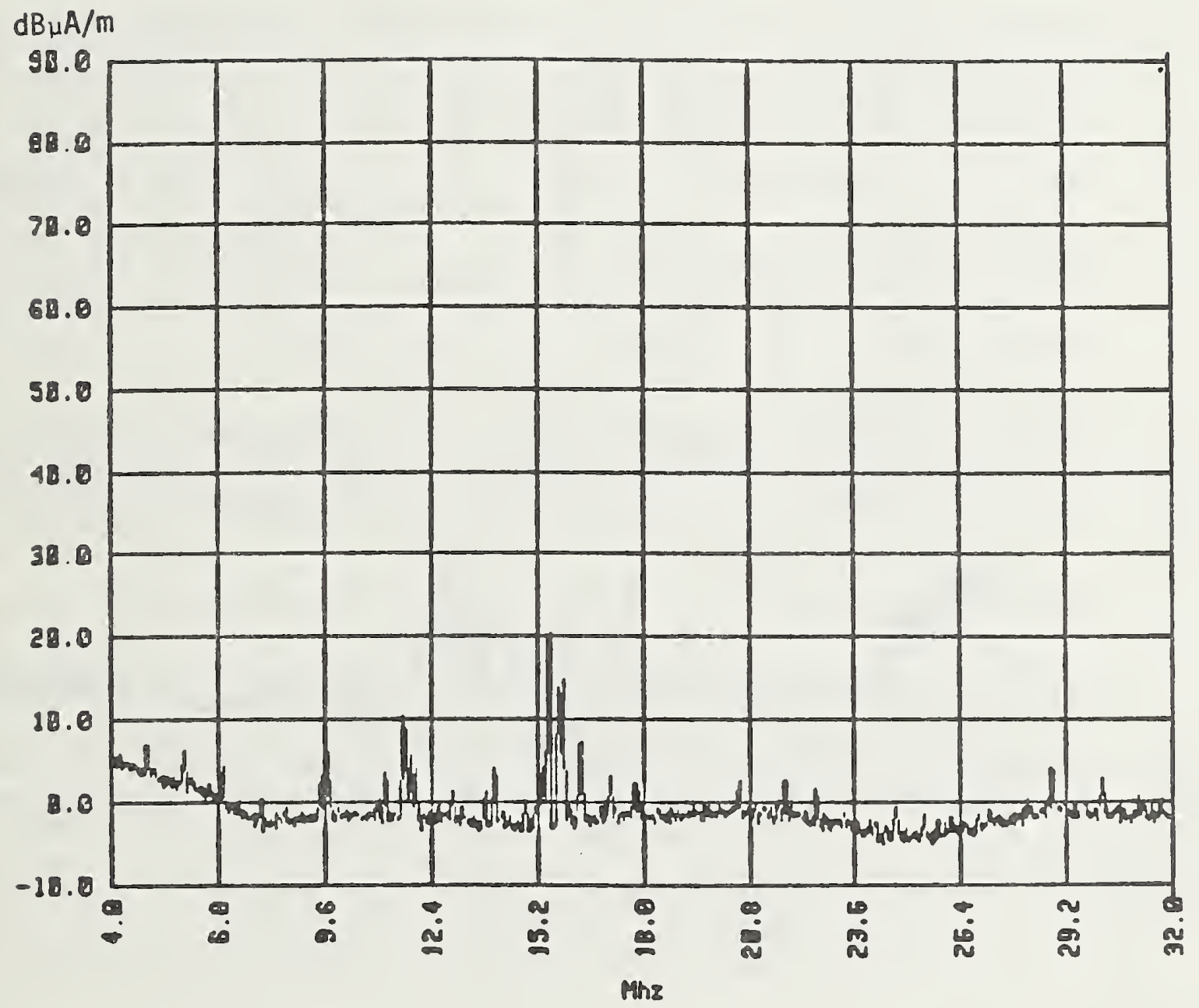

Figure 10. File 65, $4 \mathrm{MHz}-32 \mathrm{MHz}$, Horizontal N-S Moment, H-field, Reference Level $97 \mathrm{~dB} \mu \mathrm{V}, \mathrm{RBW} 30 \mathrm{kHz}, \mathrm{VBW} 30 \mathrm{kHz}, 84 \mathrm{millisecond} \mathrm{sweep} \mathrm{time,}$ Ambient, Rail Hot, Location 2. 


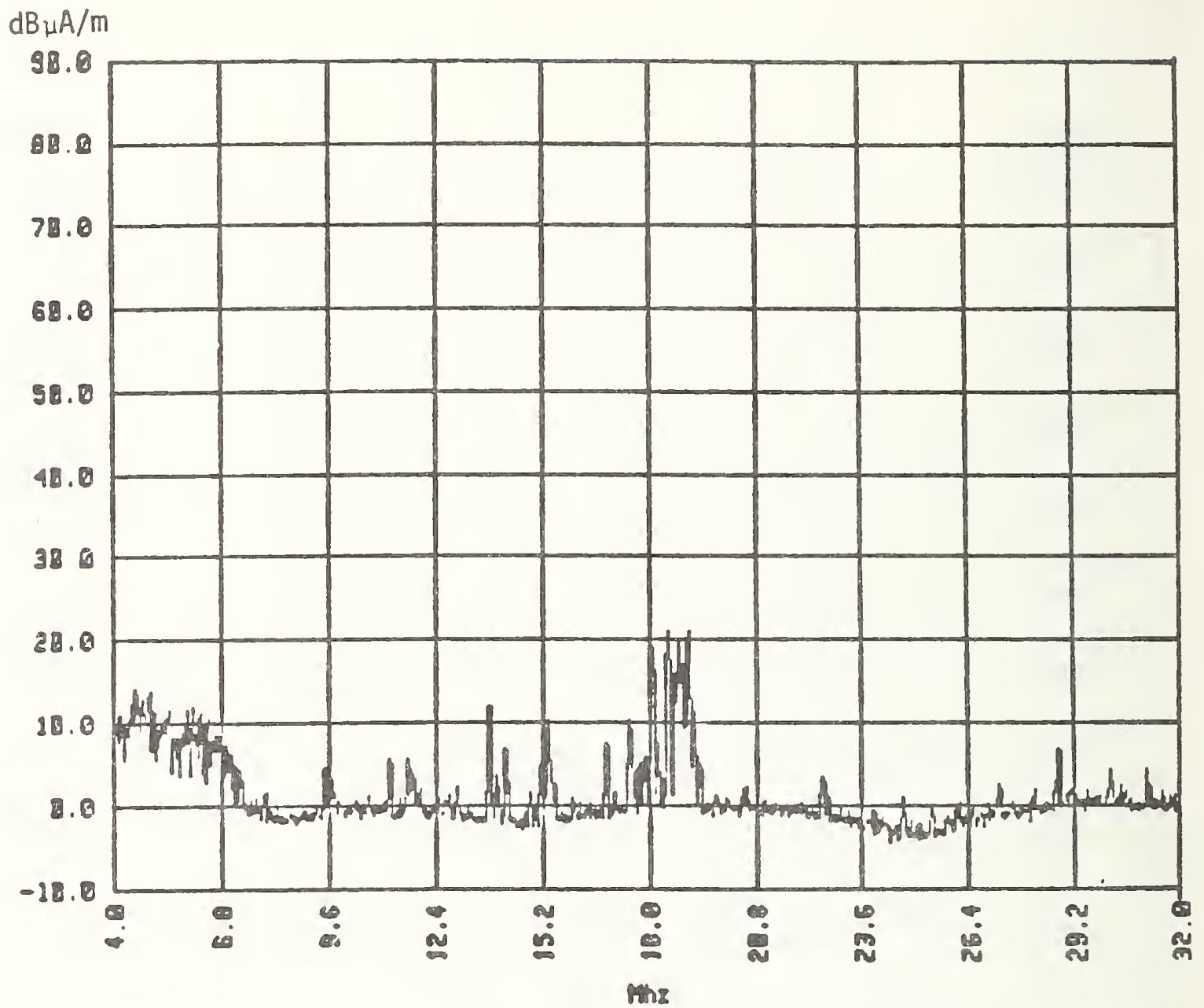

Figure 11. File 67,4 MHz - $32 \mathrm{MHz}$, Horizontal N-S Moment, H-field, Reference Level $97 \mathrm{~dB} \psi \mathrm{V}, \mathrm{RBW} 30 \mathrm{kHz}, \mathrm{VBW} 30 \mathrm{kHz}, 84$ millisecond sweep time, Maximum Acceleration, Location 2. 
NBS.114A (REV. 2॰8C)

U.S. DEPT. OF COMM.

BIBLIOGRAPHIC DATA

SHEET (See instructions)

4. TITLE AND SUBTITLE

1. PUBLICATION OR REPORT NO.

NBSIR 82-1669

Measurement of Electromagnetic Radiation from Electric-Rail Cars

5. AUTHOR(S)

John W. Adams

6. PERFORMING ORGANIZATION (If joint or other than NBS, see instructions)

7. Contract/Grant No.

NATIONAL BUREAU OF STANDARDS

DEPARTMENT OF COMMERCE

8. Type of Report \& Period Covered

WASHINGTON, D.C. 20234

9. SPONSORING ORGAIHZATHOH HAAME AHD COMFLETE ADDRESS (Strect, CIty, Stote, ZIP)

Department of Transporation

Research and Special Programs Administration

Transportation Test Center

Cambridge, Massachusetts 02142

10. SUPPLEMENTARY NOTES

Document describes a computer program; SF-185, FIPS Software Summary, is attached.

11. ABSTRACT (A 200-word or less factual summary of most significant information. If document includes a significant bibliography or literature survey, mention it here)

Existing Electromagnetic Compatibility (EMC) standards are not directly applicable for measuring Electromagnetic Interference (EMI) from an electric-rail vehicle. This report describes a measurement system and procedure that have potential for making the needed improvements. This system and procedure need further evaluation, use, and improvement before they could be considered for general use. The problems that were considered are discussed, and those that need additional work are given. Sample measured data from a Metropolitan Atlanta Rapid Transit Authority (MARTA) rail car are given. The measurements were performed at the Department of Transportation Test Center near Pueblo, Colorado.

12. KEY WORDS (Six to twelve entries; alphabetical order; capitalize only proper names; and separate key words by semicolons) EMC; EMI; electric-rail vehicle; EM radiation of electric-rail cars;

13. AVAILABILITY

X] Unlimited

For Official Distribution. Do Not Release to NTIS

Order From Superintendent of Documents, U.S. Government Printing Office, Washington, D.C. 20402.

Order From National Technical Information Service (NTIS), Springfield, VA, 2216I
14. NO. OF PRINTED PAGES

24

15. Price

$\$ 6.00$ 


